\title{
Regulation of human MAPT gene expression
}

\author{
Marie-Laure Caillet-Boudin*, Luc Buée, Nicolas Sergeant and Bruno Lefebvre
}

\begin{abstract}
The number of known pathologies involving deregulated Tau expression/metabolism is increasing. Indeed, in addition to tauopathies, which comprise approximately 30 diseases characterized by neuronal aggregation of hyperphosphorylated Tau in brain neurons, this protein has also been associated with various other pathologies such as cancer, inclusion body myositis, and microdeletion/microduplication syndromes, suggesting its possible function in peripheral tissues. In addition to Tau aggregation, Tau deregulation can occur at the expression and/or splicing levels, as has been clearly demonstrated in some of these pathologies. Here, we aim to review current knowledge regarding the regulation of human MAPT gene expression at the DNA and RNA levels to provide a better understanding of its possible deregulation. Several aspects, including repeated motifs, CpG island/ methylation, and haplotypes at the DNA level, as well as the key regions involved in mRNA expression and stability and the splicing patterns of different mRNA isoforms at the RNA level, will be discussed.
\end{abstract}

Keywords: Tau, Tauopathy, MAPT, Alzheimer's disease, Repeat sequences, CpG islands, Tau haplotype, Tau promoter, Tau splicing

\section{Introduction}

Tau proteins are expressed primarily in the brain and, more precisely, in neurons. These proteins were discovered in 1975 and identified as important mediators of cerebral microtubule polymerization and stabilization [1] (reviewed in [2, 3]). Since then, other roles for Tau proteins have been demonstrated. Tau is involved in axonal transport (reviewed in $[4,5]$ ), synaptic plasticity/function (reviewed in [6, 7]) and nucleic acid protection $[8,9]$, depending on its cellular localization (cell body/axon, cytoplasmic membrane, or nucleus).

The functional importance of Tau is underscored by the involvement of Tau deregulation in neurodegenerative diseases. Aggregation of hyperphosphorylated Tau proteins in degenerating neurons, which leads to the formation of neurofibrillary tangles, occurs in a group of pathologies termed tauopathies (reviewed in [3]). The relationship between Tau proteins and pathophysiology is supported by the identification of autosomal dominant mutations in the Tau gene, MAPT, in various tauopathies, such as frontotemporal dementia with parkinsonism linked to chromosome 17 (FTDP-17) (reviewed in $[10,11])$. Although certain tauopathies are clearly pure neurodegenerative diseases, such as Alzheimer's disease

\footnotetext{
* Correspondence: marie-laure.caillet@inserm.fr

Univ. Lille, UMR-S 1172, Inserm, CHU, 59000 Lille, France
}

(AD), progressive supranuclear palsy (PSP), corticobasal degeneration $(\mathrm{CBD})$, and FTDP-17, some are associated with the development of other pathologies, such as arteriovenous malformation [12], brain tumors (such as ganglion cell tumors) [13, 14], viral infection (such as subacute sclerosing panencephalitis (SSPE) [15] and postencephalitic parkinsonism [16]), developmental abnormalities (verrucose dysplasia [17]), Down syndrome [18], myotonic dystrophy (DM) [19], parkinsonism-dementia of Guam [16, 20], traumatic brain injury [21, 22], and Huntington's disease [23].

Tau isoforms are translated from alternatively spliced mRNA, and some or all of these isoforms aggregate, depending on the pathology (reviewed in [3]). Deregulated Tau expression and missplicing have been reported in several pathologies. The direct involvement of a splicing defect has been clearly demonstrated for FTDP-17 and DM types 1 and 2 (reviewed in [24]). Some patients with amyotrophic lateral sclerosis (ALS) or frontotemporal lobar dementia (FTLD) exhibit the nearly complete absence of Tau protein in the cortex despite normal Tau mRNA expression. These latter two pathologies, ALS and FTLD, are characterized by the presence of ubiquitin-positive aggregates composed of TDP-43 (transactive response DNA binding protein $43 \mathrm{kDa}$ ) [25-27], as reviewed in [28]. Furthermore, MAPT is a major candidate involved in the mechanism of $17 \mathrm{q} 21.31$ microdeletion syndrome, a 
pathology characterized by the microdeletion of a small chromosomal region (from 650 to $1,608 \mathrm{~kb}$ ) containing several genes, including $M A P T$. The symptoms of $17 \mathrm{q} 21.31$ microdeletion syndrome include mental retardation, hypotonia and characteristic facial features. Pathological phenotypes have also been associated with microduplications or microtriplications containing MAPT [29-32]. One of the single-nucleotide polymorphisms (SNPs) within the MAPT locus has been found to be associated with $\mathrm{AD}$ in patients without ApoE e4 [33]. The MAPT locus is an important genetic risk factor for Parkinson's disease (PD) [33-35]. Taken together, these data demonstrate the complexity of Tau expression in the brains of healthy individuals and patients with the above-mentioned diseases.

More recently, several reports have suggested that Tau interferes with certain pathologies involving tissues other than the brain. For example, Tau aggregation has been reported in the muscles of patients suffering from inclusion body myositis (IBM), an inflammatory muscle disease $[36,37]$. Furthermore, Tau expression may have a prognostic or predictive value in some cancers affecting various tissues, such as breast [38, 39], prostate [40, 41], ovary [42, 43], bladder [44], and stomach cancers [45]. Tau expression could be related to certain sub-types of cancer; for example, it is increased in hormonedependent breast cancer $[39,46]$. Such an increase in Tau expression may result in resistance to microtubuletargeting drugs [43, 47-56].

Despite the importance of the deregulation of Tau expression/metabolism in many pathologies, the regulation of the expression of the MAPT gene, which encodes Tau protein, has been the subject of few articles; more articles have focused on the function of Tau protein or its roles in various pathologies. The most commonly studied aspects include MAPT haplotypes and Tau RNA splicing because of their involvement in certain tauopathies (for examples, see reviews [57-61]). Research regarding the epigenetic regulation of Tau expression is increasing. However, some aspects of Tau gene expression, such as the possible existence of different promoters and the potential role of the repeated motifs found in all MAPT sequences, have rarely been studied, despite the availability of abundant data in bioinformatics databases. The aim of this review is to provide a global synthesis of knowledge regarding the regulation of human $M A P T$ gene expression at the DNA and RNA levels by evaluating data from the literature and bioinformatics databases. Several aspects will be discussed, including repeated motifs, CpG island/methylation, and haplotypes at the DNA level as well as the key regions involved in mRNA expression and stability (i.e., the $5^{\prime}$ and $3^{\prime}$ untranslated regions [UTRs]) and the splicing patterns of different mRNA isoforms at the RNA level.

\section{DNA regulatory elements involved in Tau expression}

The human MAPT gene is a long $(134 \mathrm{~kb})$ gene located on chromosome $17 \mathrm{q} 21$. Its sequence is well conserved among mammals, exhibiting 97 to $100 \%$ homology with primates. This observation is quite surprising considering the specific human susceptibility to developing tauopathies.

\section{Repeated sequences}

Numerous repeated sequences are spread throughout the human genome. These sequences can be classified into two groups: transposons and satellites.

\section{Transposon-type repeats}

Transposon-type repeats can be classified into the following four categories: short interspersed nuclear elements (SINEs), long interspersed nuclear elements (LINEs), DNA transposons, and transposable elements with long terminal repeats (LTRs). All 4 categories of this type of repeat are found in the MAPT gene. Generally, SINEs are the most numerous, and among them, Alu sequences are the most frequent. Alu elements are 300 -nucleotide (nt) sequences that occupy over $10 \%$ of the human genome. These sequences contribute to genomic instability by eliciting gene mutations, altered gene expression and transcript splicing or by generating a new gene segment [62]. Among the $83 \mathrm{Alu}$ sequences identified in the MAPT gene using the TranspoGene database [63], 56 are on the sense strand and 27 are on the antisense strand. These sequences are located within intronic sequences, independent of the considered isoform. Alu sequences have also been localized to the $M A P T$ promoter in a region upstream of the first exon (E0) $[64,65]$. In addition, other types of repeated sequences have been identified in the MAPT gene, some of which are located in the promoter [64]. However, the impact of these sequences on promoter activity is not well understood.

\section{Simple sequence repeats (SSRs)/microsatellites and minisatellites}

SSRs are short repeated sequences that are abundant throughout eukaryote genomes, are localized to intergenic or genic regions, and constitute an important class of genetic markers. Depending on the length of the repeat, SSRs can also be called microsatellites ( 1 to 13 bases per repeat) or minisatellites (14 to 100 bases per repeat) [66]. The roles of these microsatellites/minisatellites are varied and are not all well understood. However, some effects of these motifs have begun to be reported. For example, dinucleotide motifs have been identified as part of a general enhancer feature (i.e., non-cell type-specific enhancers) [67]. Furthermore, SSRs affect DNA structure, gene 
expression and genomic stability and can lead to a toxic gain-of-function in an RNA or protein when the number of repeats increases, as has been observed in a growing number of neurodegenerative diseases. For example, DM and Huntington's disease involve an RNA and protein, respectively, with a toxic gain of function (reviewed in [68, 69]).

SSRs can be found throughout the MAPT gene using the Tandem Repeats Finder program (TRF/UCSC) [70]. Interestingly, the first genetic marker identified as overrepresented in PSP patients was a dinucleotide repeat (11xTG, named $\left.\mathrm{TG}_{11}\right)$ downstream of exon 9 ([71, 72], reviewed in [60]). Some of these repeats are clearly distinguishable based on the following features: (i) their repeat length (4 sequences are longer than $20 \mathrm{nt}$, and the longest sequence is $58 \mathrm{nt}$ ); (ii) their localization throughout the gene (shorter sequences of less than $20 \mathrm{nt}$ are located before exon E4, whereas the longest sequence, which is more than $20 \mathrm{nt}$ long, is located after E4); (iii) their proximity to alternative exons; and (iv) the repeat lengths of certain imperfect repeats, such as those of the dinucleotides $\mathrm{TA}$ or GT in intron $0\left(\mathrm{TA}_{356}, \mathrm{GT}_{187}\right)$ (Fig. 1). A 58-nt motif $\left(\mathrm{SSR}_{58}\right)$ that is repeated twice is located immediately upstream (precisely $10 \mathrm{nt}$ ) of the alternatively spliced E10 [73, 74]. Interestingly, the copy number of this long repeat seems to influence the splicing pattern of this exon [73]. Although no functional role has been demonstrated, notably, a dinucleotide GT repeat $\left(\mathrm{x} 22: \mathrm{GT}_{22}\right)$ has been identified immediately downstream of E0 (precisely 362 nt from E0) in the human gene, as first reported by Andreadis et al. [75]. Compared with the mouse sequence, half of this human TG repeat corresponds with an insertion in a sequence that is well-conserved (76 \% homology) between human and mouse E0. However, a similar 23-repeat TG sequence also exists in intron 0 of mouse MAPT, but it is located $7301 \mathrm{nt}$ downstream instead of 362 nt downstream of E0 in a non-homologous region of the human gene. We also observed 4 different short regions containing CATC or CCAT repeats located immediately downstream (from 46 to $1200 \mathrm{nt}$ ) of the internal exon
$\mathrm{E} 1 \mathrm{~A}$, between $\mathrm{E} 1$ and $\mathrm{E} 2$ in the only $M A P T$ transcript that is potentially subjected to nonsense-mediated decay (NMD) (MAPT-011 ENST00000571311) (Fig. 1, Fig. 4b).

\section{CpG islands and methylation CpG islands}

As determined by CpG Islands Track Settings (UCSC), one long CpG island spans approximately $300 \mathrm{nt}$ upstream to $3000 \mathrm{nt}$ downstream of E0 in human MAPT (the total $[\mathrm{G}+\mathrm{C}]$ increases to $75 \%$ around the transcription start site, with as high as $10 \%$ CpG dimers) [76-78]. This $\mathrm{CpG}$ island $\left(\mathrm{CpG}_{300}\right)$ is located in the promoter region (Fig. 1, Fig. 2). Two additional but more limited sequences are present, including one containing 27 CpGs $\left(\mathrm{CpG}_{27}\right)$ that is located $13 \mathrm{~kb}$ upstream of $\mathrm{E} 1$ and another containing $21 \mathrm{CpGs}\left(\mathrm{CpG}_{21}\right)$ that is located immediately upstream of E4A (UCSC Genome Browser [79]). The $\mathrm{CpG}_{21}$ island is situated at the beginning of the short transcript MAP-010/ENST00000576238 (Fig. 1, Fig. 4b). Thus, we cannot ignore the possibility that this $\mathrm{CpG}$ island may be involved in the transcriptional regulation of this minor transcript (see section 3.1.3). However, no histone H3 lysine 4 trimethylation, another feature of promoter regions, was found in this third $\mathrm{CpG}$ island $\left(\mathrm{CpG}_{21}\right)$ using $\mathrm{CpG}$ Islands Track Settings (UCSC genome browser) [76, 80]. In addition to these three $\mathrm{CpG}$ islands, other CpG islands can be identified using less restrictive conditions. For example, one CpG island was identified in exon E9 (198 nt/266) using MethPrimer (http://www.urogene.org/methprimer) $[75,81]$. This type of CpG island is a $3^{\prime}$ island as defined by Gardiner-Garden and Frommer [76]; however, no methylation studies of this type of island have been reported. Another $\mathrm{CpG}$ island has been predicted in the coding region of the last exon, E13, using the same MethPrimer tool [81].

\section{DNA methylation}

Effective DNA methylation has been identified in both $\mathrm{CpG}_{300}$ and $\mathrm{CpG}_{27}$ islands; however, functional studies have focused primarily on the $\mathrm{CpG}_{300}$ island located around $\mathrm{E} 0$. In the brain, MAPT methylation varies according to the area analyzed $[82,83]$. Interestingly, DNA

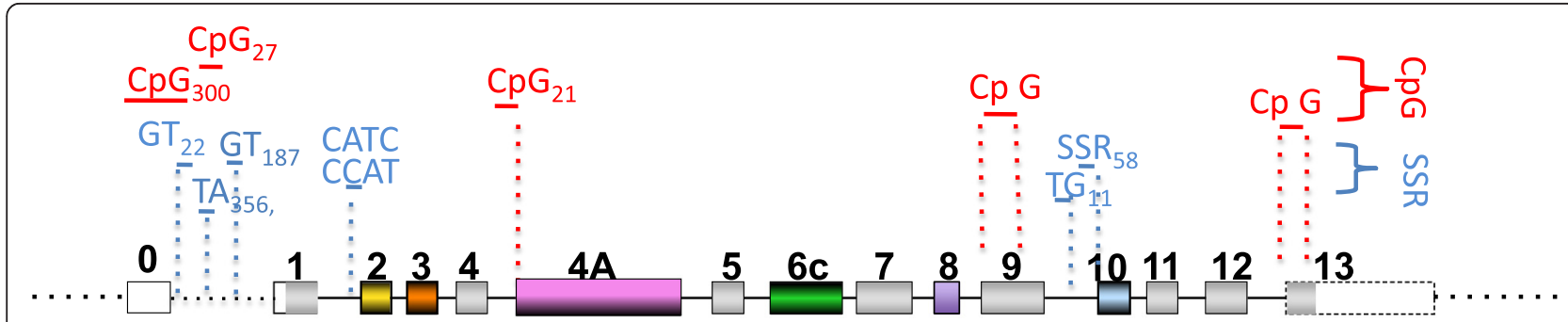

Fig. 1 DNA satellite sequences and CpG islands in the MAPT gene. Only the repeats discussed in the text are indicated. The complete list can be found on the UCSC site. White, non-coding regions; color, coding regions; gray, constitutive coding exons. Yellow, orange, pink, green, purple and blue represent the alternative exons $2,3,4 \mathrm{~A}, 6,8$ and 10 , respectively 


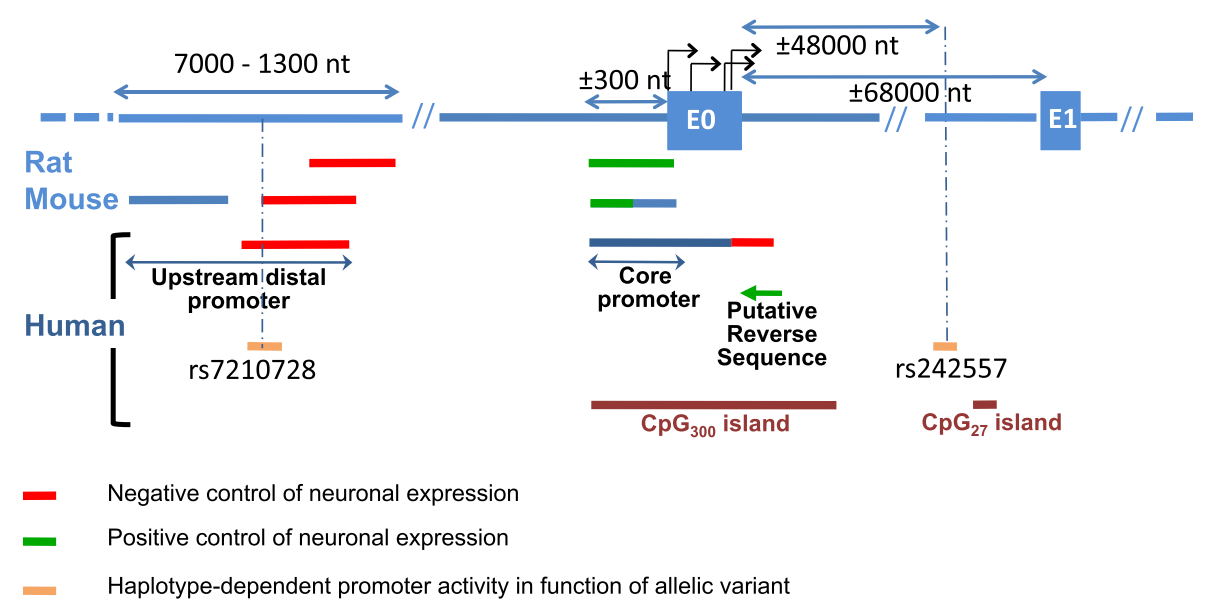

Fig. 2 Organization of the rat, mouse and human Tau promoters. The lengths of the various regions of the promoter are not representative of their precise localizations but are dependent on the cloning technique. Thus, differences in the length of a determined region among species are not significant. Note the influence of allelic variants on promoter activity. CpG islands present in the promoter are indicated

hypomethylation has been observed in various pathologies, such as PSP, AD and PD [82, 83]. These differences have been observed in neuronal and non-neuronal cells in cases of sporadic AD [83]. MAPT hypermethylation leads to decreased Tau expression, suggesting that the hypomethylation observed in $\mathrm{AD}$ is associated with an increase in Tau protein expression and thus could participate in aggregation seeding and pathological propagation through the brain via a prion-like mechanism [83]. Concerning PD, hypermethylation in the cerebellum (the region spared in PD) and hypomethylation in the putamen (the region with the highest level of PD pathology) are consistent with reports on $\mathrm{AD}$, with a possible neuroprotective effect of DNA hypermethylation by reducing $M A P T$ expression. Furthermore, the neuroprotective effect of MAPT hypermethylation is somewhat illustrated by the fact that higher methylation in Parkinson leukocytes is associated with lateonset PD [82]. However, some contradictory results have been reported, including no changes in methylation in $\mathrm{AD}$, PD and some cases of frontotemporal dementia (FTD) [84]. These differences might have resulted from the analysis method used (microarray analysis/pyrosequencing) and/or the brain region analyzed (hippocampus, frontal cortex/ cerebellum, parietal cortex and temporal cortex).

\section{Haplotypes}

Tau haplotypes and neurodegenerative disease development

More than 120 nucleotide changes across the MAPT gene have now been described, $60 \%$ of which are primarily localized to two clusters in introns 9 and 10 [85]. An atypical pattern of linkage disequilibrium results in 2 major haplotypes: $\mathrm{H} 1$ and $\mathrm{H} 2$. Among the genetic variations, the $\mathrm{H} 2$ haplotype differs from $\mathrm{H} 1$ by the deletion of a $238 \mathrm{bp}$ sequence upstream of Tau exon 10 (reviewed in [60]). Another feature of the $\mathrm{H} 2$ haplotype is the inversion of a $900 \mathrm{~kb}$ sequence, most likely due to non-allelic homologous recombination between the long coding repeats (LCRs) that surround this region [86, 87]. The frequency of $\mathrm{H} 2$ inversion differs between ethnic groups; the H2 haplotype is found primarily in Europeans and southwest Asians. Notably, the presence of various homologous LCRs in this short genomic region surrounding the MAPT locus could trigger other genomic rearrangements, leading

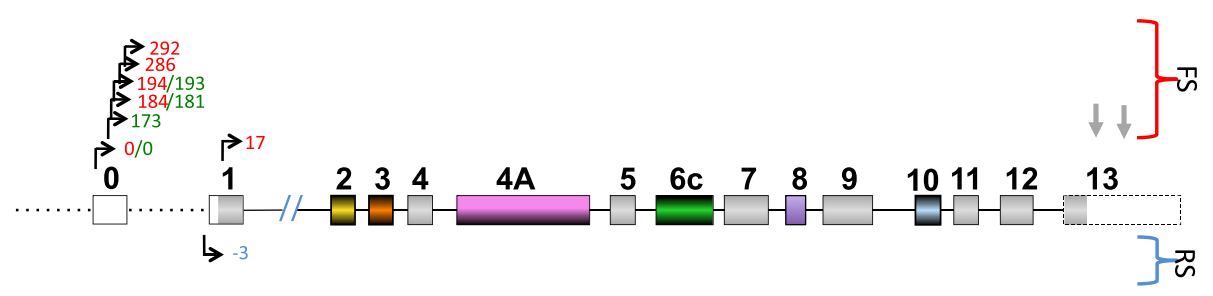

Fig. 3 Transcription initiation sites (black perpendicular arrow) and termination sites (simple gray arrow). These sites enable the expression of the complete Tau transcript/protein. For other sites, see Fig. 4b. Red numbers: initiation sites according to the database. Green numbers: initiation sites described in [77]. FS: forward strand, RS: reverse strand 
to microdeletion/microduplication/microtriplication of this short genomic region [29-32]. H2 inversion seems to be a risk factor for genomic rearrangements such as microdeletions [88].

The H1 haplotype is relatively heterogeneous compared with $\mathrm{H} 2$. A total of 24 SNPs in the MAPT gene vary in the $\mathrm{H} 1$ background haplotype and enable classification of the gene into H1 sub-variants [89]. H1 haplotypes or sub-haplotypes are associated with increased risks of developing certain neurodegenerative diseases. Although first established for PSP and CBD, the list of pathologies is increasing and includes the following: neurofibrillary tangle-predominant dementia, PD, AD, primary progressive aphasia, and argyrophilic grain disease [72, 89-97]. However, Sobrido et al. have reported no association between the H1 haplotype and FTD [98] and a slight, but not significant, increase in the $\mathrm{H} 2$ haplotype frequency has been reported in Pick disease [99].

Notably, DNA methylation is increased in the H1 haplotype compared with that in the $\mathrm{H} 2$ haplotype and can be observed in both the blood and brain [82, 100]. Furthermore, differential methylation (hypomethylation or hypermethylation, depending on the analyzed site) could play a role in the association of the $\mathrm{H} 1$ haplotype with the development of PSP, particularly for the methylation sites within the $17 \mathrm{q} 21.31$ region where the $M A P T$ gene is located [100].

\section{Functional effects of the $\mathrm{H} 1$ haplotype on pathology}

The functional effects of the H1 haplotype on the development of neurodegenerative diseases have been investigated at different levels.

PSP and CBD, the first pathologies associated with the H1 haplotype, display particular patterns of Tau isoform expression. Indeed, Tau isoforms containing sequences encoded by the alternative exon 10 of Tau mRNA are preferentially found in degenerating neurons, suggestive of altered Tau splicing. Consistent with these observations, the $\mathrm{H} 1 \mathrm{C}$ sub-haplotype found predominantly in these pathologies seems to favor exon 10 inclusion compared with the H2 haplotype [101]. Caffrey et al. have also reported an increase in exon 3 inclusion for the $\mathrm{H} 2$ haplotype [102]. Further, these authors have suggested that the E3-encoded sequence could have a protective effect against these pathologies, consistent with the observed decrease in the fibrillar extension of Tau proteins when the E3-encoded sequence is present [103].

Using luciferase assays, the $\mathrm{H} 1$ haplotype promoter has been shown to be more efficient at promoting Tau transcription compared with the H2 promoter [104-106]; however, these data are somewhat controversial because allele-specific expression experiments have not detected a difference in expression between these two haplotypes
[104-106]. Notably, using this method, the authors have shown a decrease in $\mathrm{H} 1$ haplotype expression during aging.

Some polymorphisms have been demonstrated to interfere with $M A P T$ expression. Two allelic variants located upstream of E0 (rs7210728) ( $\pm 3000 \mathrm{nt})$ and downstream of E0 (rs242557) ( $\pm 48000 \mathrm{nt})$ have been identified as modulators of promoter activity according to haplotype (H1 versus H2) [101, 106] (Fig. 2). Notably, the second polymorphism, rs242557, is located only approximately $6800 \mathrm{nt}$ upstream of the second $\mathrm{CpG}_{27}$ island (Fig. 1, Fig. 2).

The relationship between MAPT haplotype and Tau and/or $\alpha$-synuclein pathologies has also been investigated by studying brains affected by AD or $\alpha$-synucleinopathies, including PD and dementia with Lewy Bodies (LBs). Surprisingly, the $\mathrm{H} 1$ haplotype may be protective against Tau aggregation but favors $\alpha$-synuclein aggregation in LBs [107-109]. However, the results may be dependent on the studied brain area, the pathology type, the aggregate type and other factors associated with these pathologies, such as ApoE/ $\alpha$-synuclein haplotype and amyloid aggregation. Thus, additional studies are needed to determine whether the MAPT haplotype has an effect on Tau or $\alpha$-synuclein deposition. Another method used to ascertain the potential relationship between Tau haplotype and tauopathy development involves examining the possible relationships between $M A P T$ haplotypes and biological markers. A diagnostic test first developed for AD based on three major biomarkers (amyloid peptide $A \beta 1-42$, total Tau (t-Tau) and Tau phosphorylated at Thr181 (p-Tau)) of AD found in CSF has been proposed [110]. Unfortunately, conflicting data have been obtained for the $\mathrm{H} 1 \mathrm{C}$ subhaplotype regarding Tau levels in CSF $[111,112]$. These two groups have also reported correlations between specific MAPT SNPs and Tau levels in CSF. Among these SNPs, at least some may be associated with an earlier stage at onset [111]. More recently, an N-terminal fragment of Tau has been identified in CSF as a new diagnostic marker for various neurodegenerative diseases associated with cognitive impairment [113]. If this result is confirmed, then investigating the relationship between Tau haplotypes and this new marker would be of interest.

\section{Regulation of Tau RNA expression and splicing}

Tau mRNA expression was initially identified in the brain and, more precisely, in neurons by both northern blot and in situ hybridization analyses; it has since been detected in various tissues, including the cerebellum, kidney, muscle and testis, using more sensitive methods such as RT-PCR, microarray and RNA-Seq [57, 114-116]. However, although Tau protein expression in peripheral tissues has been clearly observed in rats [116], very little data concerning such expression in human tissues have been 
reported [117], with the exception of reports of Tau protein expression in pathological peripheral tissues $[37,41,118]$.

Mature Tau transcripts contain up to 16 exons $[3,57]$. The different exons have been identified and numbered, corresponding to their locations within RNA sequences from different animal, primarily human, bovine and murine, models. The first exon is generally named exon 0 (E0) in the literature, and exon 4A corresponds to the alternative exon located between exons 4 and 5. The exon numbers provided in the databases must be carefully considered when determining the functions of analyzed transcripts because different exons may be assigned the same number depending on the transcript analyzed.

Three Tau transcripts of $2 \mathrm{~kb}, 6 \mathrm{~kb}$, and $9 \mathrm{~kb}$ in length are encoded by the MAPT gene (reviewed in [57]). These transcripts differ from one another by their splicing patterns, as demonstrated by the differences between the 6 and $9 \mathrm{~kb}$ transcripts [119], and their polyadenylation sites (2 kb versus $6 \mathrm{~kb}$ ) [120]. The abundance of data in databases largely confirms the observed variations in splicing patterns and polyadenylation sites but also suggests the existence of several promoters, as detailed below.

\section{5' UTR/MAPT promoter}

\section{MAPT promoter identification in the $E O$ region}

The MAPT promoter has been studied primarily in three different models, namely human, rat and mouse models. The MAPT promoter is characterized by a high $\mathrm{G}+\mathrm{C}$ content as well as by the absence of TATA and CAAT boxes $[65,77,121]$. Several regions have been determined to play important roles in Tau transcription (Fig. 2).

First, the "core" promoter is located immediately upstream of the first exon (exon E0, previously named exon -1) (Fig. 2) [64, 65, 77, 101, 121]. More detailed studies of rat and mouse models have enabled differentiation between the two sub-sequences in this core region [121, 122] (Fig. 1). The sequence located $5^{\prime}$ of the core sequence is involved in neuronal-specific expression in rats and mice but not in humans, whereas expression of the 3 ' sequence is not tissue dependent [77, 121-123]. However, this apparent difference in the neuronal specificity of the core promoter between mice and humans may be due to differences in the cell type and the length of the promoter sequence used in constructs, as suggested by Maloney and Lahiri [64]. These authors have reported the influence of E0 on human promoter activity and have identified a neuronal-specific sequence that includes the last $10 \mathrm{nt}$ of E0 and the first $200 \mathrm{nt}$ of the intronic sequence located immediately downstream that negatively regulates promoter activity (Fig. 2).
Other distal sequences (approximately -7000 to $-1500 \mathrm{nt}$ upstream of exon E0) are involved in promoter activity [64, 101, 121] (Fig. 2). The 3' end of this sequence (approximately -3000 to $1500 \mathrm{nt}$ ) negatively regulates Tau expression in rats and humans $[64-66,101,121]$. The $5^{\prime}$ end of this sequence (approximately -7000 to $3000 \mathrm{nt}$ ), which has only been studied in mice, is also involved in promoter activity [121]. In addition, a putative reverse sequence located immediately downstream of E0 might be involved in human MAPT regulation (Fig. 2) [64]. However, these authors could not exclude interference from another promoter because of identification of a hypothetical gene, LOC100128977, immediately upstream of and in the opposite orientation as the MAPT gene [124].

According to the technique used, several initiation sites for Tau transcription have been reported in both rats and humans [65, 77]. The human transcript sequences published in databases confirm the diversity of the transcription start sites. However, some discrepancies exist between the sites described in the literature and those in databases. In particular, the initiation sites of the published sequences are located in E0, whereas the Ensembl database shows that various initiation sites are present all along the gene in addition to those in E0 (Fig. 3, Fig. 4b) [125]. Three of these identified sites are common between the literature and databases.

\section{Trans factors}

As demonstrated by electrophoretic mobility shift assay (EMSA), the transcription factors SP1 and AP2 bind to the Tau core promoter region and are necessary for promoter activity [121, 122]. Another DNA sequence located between the SP1 and AP2 sites influences promoter activity; however, the transcription factor involved remains to be identified [122]. EMSA has also revealed that SP1, progesterone receptor (PR) and retinoic acid receptor (RAR) bind to the human exon E0 sequence, although their functionalities remain to be demonstrated [64].

The human MAPT promoter region also contains putative binding sites for various other transcription factors, such as Nrf1, MTF1, MBF1, MepI, and GCF [64, 101]. Some of these sites are shared between the $\mathrm{H} 1$ and $\mathrm{H} 2$ haplotypes, such as the AP2 and SP1 sites mentioned above. Interestingly, among these common sites, four sites corresponding to an $A \beta$-interacting domain have also been identified in the distal region of the Tau promoter $[64,126]$. $A \beta$ is a pathological peptide generated via deregulated proteolysis of amyloid precursor protein (APP). This peptide aggregates during $\mathrm{AD}$ and leads to the observed pathology of this disease according to the amyloid cascade hypothesis. This aggregation/accumulation of $A \beta$ is not a feature common to all tauopathies, but it does occur in some, such as $\mathrm{AD}$ and Down syndrome. Several studies have suggested that the pathological effect of $A \beta$ is mediated by Tau 

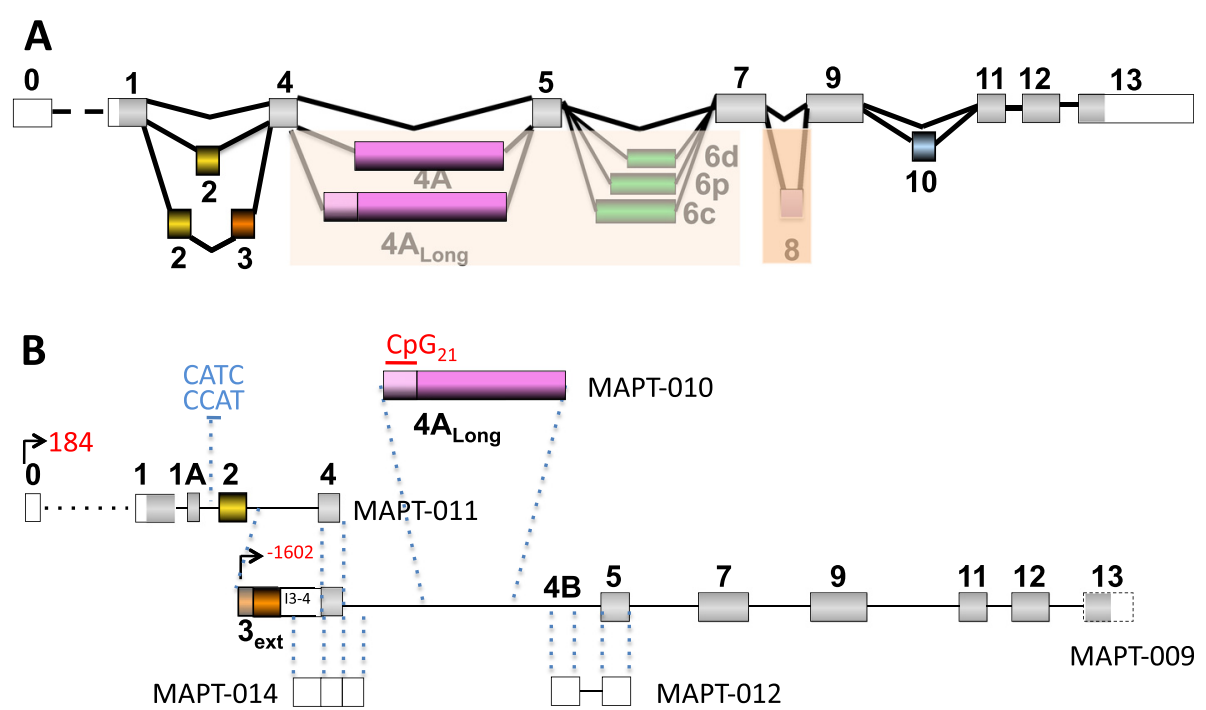

Fig. 4 Splicing patterns of human Tau transcripts. a Classical splicing pattern described in the literature. The insertion of exons $4 \mathrm{~A}$ and 6 rarely occurs in the brain (shaded in pale orange) and varies according to which 3' splice site is used. E8 insertion (shaded in dark orange) has not been reported in humans but has been described in different animal models and in the human Ensembl database. b Hypothetical splicing according to the Ensembl database. The MAPT numbers correspond to those in the Ensembl database. White, non-coding regions; gray, constitutive coding exons. Yellow, orange, pink, green, purple and blue represent the alternative exons 2, 3, 4A, 6, 8 and 10, respectively

(reviewed in $[127,128])$. Thus, determining whether the A $\beta$-interacting domain actually regulates Tau expression directly and thus participates in the development of Tau pathologies in which both amyloid and Tau aggregates are present would be of interest.

\section{Does MAPT have only one promoter?}

Alternative initiation transcripts largely contribute to transcriptome and proteome diversity, and more than $40 \%$ of genes have at least two promoters, as demonstrated in flies (reviewed in $[129,130])$. Although the region around E0 contains the only promoter for MAPT that has been described in the literature, Andreadis [57] hypothesized the existence of additional Tau promoters to explain variations observed in neuronal specificity and NGF susceptibility of Tau expression according to the different Tau transcripts [77, 119, 131]. Currently, new data are available in databases that reinforce this hypothesis; at least 6 other exons distal to E0 have been identified as the first exons of various transcripts.

One of the potential additional promoters may be associated with the initiation of transcription at exon E1. Indeed, considering the number of identified transcripts, E1 is the most frequent exon where transcription is initiated after E0 (transcripts initiated at E0: 9 and E1: 5) for the H1 haplotype, further suggesting the possible existence of an unidentified promoter. E1 is located $68000 \mathrm{nt}$ distal to E0. Similar to E0 [57], sequence analysis has revealed no TATA or CAAT consensus binding sites in E1; however, a GC box specific for SP family members is present near this exon [132].
Indeed, one potential SP1 site and five sites for AP- $2 \alpha$ binding have been identified 200 nt upstream of E1 using the ALGGEN server [133]. The absence of E0 would result in a change in the $5^{\prime}$ UTR length but would not alter the coding sequence because E0 is a non-coding exon, while E1 is a partially coding exon (Fig. 1). On the reverse strand (H2 haplotype), transcripts listed in the Ensembl database begin primarily with E1 [125] (Fig. 3).

The other initiating exons near the E2, E3, E4A and E5 regions are located more than $10,000 \mathrm{nt}$ and up to 25,000 nt distal to E1, suggesting that more than one alternative promoter may exist. Interestingly, the $\mathrm{CpG}_{21}$ island is located immediately upstream of E4A at the beginning of the short transcript MAP-010/ENST00000576238, as described above in the CpG island section (Fig. 4b).

\section{Tau splicing}

Here, we will not describe the splicing mechanisms in detail because they have been discussed in previous reviews; however, we will focus on the Tau splicing pattern because splicing is an indirect mechanism of protein function modulation via sequence modification $[24,57,61,134]$.

\section{Published data}

Tau alternative splicing is dependent on the developmental stage, tissue and species.

Central nervous system (CNS) The following are generally recognized facts regarding Tau splicing in the human CNS. 
(i) In the fetal brain, only one isoform is predominantly expressed, with insertion of the constitutive coding exons (E1, E4, E5, E7, E9, E11, E12, and E13/14). E1 is considered a coding exon because it contains the initiating ATG codon. In addition, there are no reports in the literature suggesting the presence of non-coding E0 during the fetal stage $[3,57,135,136]$.

(ii)E2, E3 and E10 are specific to the adult brain (Fig. 4a). Consistent with this statement, 6 protein isoforms have been identified in the human adult brain that contain sequences encoded by exon 2, exon 3 and/or exon 10 . Generally, these 6 isoforms are named 2N3R, 1N3R, $0 \mathrm{~N} 3 \mathrm{R}, 2 \mathrm{~N} 4 \mathrm{R}, 1 \mathrm{~N} 4 \mathrm{R}$, and $0 \mathrm{~N} 4 \mathrm{R}$. The designations $0 \mathrm{~N}$, $1 \mathrm{~N}$ and $2 \mathrm{~N}$ indicate the exclusion of $\mathrm{E} 2$ and $\mathrm{E} 3$, the inclusion of E2 and the inclusion of both E2 and E3, respectively. Notably, the insertion of E3 is dependent on the presence of $\mathrm{E} 2$, which corresponds with an atypical feature of the splicing event. Globally, E3 inclusion can be considered a rare event compared with E2 insertion or complete Tau transcription, as evidenced by RT-PCR [114, 137]. Conversely, 3R and $4 \mathrm{R}$ indicate the exclusion and inclusion of E10 $[115,138]$, respectively, which has been previously reviewed $[3,139]$.

Peripheral tissues Considering peripheral tissues, including the peripheral nervous system (PNS), the alternative exons described above are often included with other exons that are nearly absent in the CNS. Indeed, exon $4 \mathrm{~A}(\mathrm{E} 4 \mathrm{~A})$ is present specifically in the PNS and retina, and exon 6 (E6) is found in the spinal cord and skeletal muscle. Interestingly, the lengths of these latter two exons, E4A and E6, are modulated by the choice of 3' splice site. Indeed, two possible 3' splice sites exist for $\mathrm{E} 4 \mathrm{~A}\left(\mathrm{E} 4 \mathrm{~A}, \mathrm{E} 4 \mathrm{~A}_{\text {Long }}\right)$, and there are 3 splice sites for E6 (E6c, E6p, E6d) [41, 117, 137] (Fig. 4a). However, although isoforms containing $\mathrm{E}_{4} \mathrm{~A}_{\text {Long }}$, E6p, and/or E6d have been reported in the literature, they are not present in human databases (Ensembl, UCSC). These observations bring into question the frequencies at which these different 3 ' splice sites are used. Considering the possible co-insertion of alternative exons, in ENSEMBL/ UCSC sequences, E4A is always inserted when E6 or E6 and E8 are included with E2, E3 and E10. However, an E4A-containing isoform without E6 but containing E2, E3 and E10 has been cloned [140]. Furthermore, in Ensembl database, the isoforms containing exon $6 \mathrm{c}$ also contain exons 2, 3, 4A and 10 with or without exon 8, although studies by Andreadis's group have demonstrated that all combinations of E6c, E6p, and E6d with the other alternative exons are possible [141]. The inclusion of E6p and E6d results in the translation of a truncated protein that lacks microtubule-binding sites because of a change in the reading frame that introduces a stop codon. Tau proteins containing E6c- or E6d-encoded sequences have been identified in several tissues, including brain and muscle tissues, using specific antibodies [142, 143]. These new forms, although minor, could interfere with the role of Tau in axonal transport $[144,145]$. Note also the rare but possible inclusion of E6 in the fetal brain [57].

\section{Suggestions from databases}

Recent data from databases suggest that the splicing pattern of MAPT may be more complicated than suggested by the primary characteristics described above, although particular splicing events are most likely rare. Although the majority of transcripts described in databases are coding transcripts, some are not (Fig. 4b). Non-coding transcripts have been identified that correspond primarily to isoforms with the deletion of at least one constitutive exon. One such non-coding transcript (MAPT-011 ENST00000571311) (Fig. 4b) may be processed by NMD. Notably, none of these variants have been described in the literature, although they are listed in Ensembl. Their existence and potential roles (perhaps as lncRNAs) remain to be investigated and confirmed.

Splicing and H1/H2 haplotypes A comparison of the transcripts from the forward $(\mathrm{H} 1)$ and reverse $(\mathrm{H} 2)$ strands that have been published in databases such as Ensembl has revealed that the haplotype might affect some splicing events. This situation has already been reported for E10 (see the sub-chapter "Functional consequence of $\mathrm{H} 1$ haplotype on pathology").

Alternative 5' UTR/alternative first exon In the literature, E0 is always described as the first exon in all $M A P T$ transcripts. However, when analyzing different $M A P T$ transcripts in databases such as Ensembl, it is apparent that E0 can be present or absent in the H1 haplotype; thus, it may be considered an alternative exon due to alternative promoter usage. Furthermore, E0 inclusion is less frequent in the sequences of transcripts from the reverse strand (H2 haplotype) (Fig. 3). Several possible initiating transcription sites may exist in E0 as described above (see the sub-chapter regarding promoters), leading to different possible lengths of E0 and of the $5^{\prime}$ UTR because E0 is a non-coding exon (Fig. 3). According to the Ensembl database, the length of E1 may also vary depending on the first exon that is included (E0/E1). Indeed, E1, a partially coding exon, is 150 or 133 nt long when initiated from E0 or E1, respectively, on the forward strand. For H2 (the reverse strand), in the absence of E0, the length of E1 is three nucleotides longer at its $5^{\prime}$ side (153 nt) or 17 nucleotides shorter at the ATG codon (133 nt). These variations in E1 length do not 
affect the sequence of the translated protein because the $5^{\prime}$ end is non-coding; therefore, this length variation only results in modification of the $5^{\prime}$ UTR of the transcript (Fig. 2).

Additional exons The possible insertion of additional exons, although not yet identified in the published human transcripts, is suggested by data in the Ensembl database. This possibility is the case for $\mathrm{E}$ 8, which was first identified in bovines and then in certain species such as rhesus monkeys [146, 147] but has not been described in humans [148] (Fig. 4a). However, according to the Ensembl database, transcripts containing E8 include all of the alternative exons except for E0, which can be included or excluded (MAPT-203 ENST00000344290, MAPT-004 ENST00000415613). Studies of different animal species have shown that E8 insertion is possible in the absence of certain alternative exons. In particular, 4 transcripts containing E8 have been identified in cows [148]. All of these transcripts also contain E2 and E10 but lack E4A. These transcripts differ from each other by the presence or absence of E3 or E14. In mice, only one transcript (MAPT-006/ENSMUST00000106993) has been identified with E8, and this transcript contains E10 as the only other alternatively spliced exon.

New exons that have never been reported in the literature are present in certain transcripts. The insertion of most of these new exons results in truncated transcripts at the $5^{\prime}$ and/or 3' ends of Tau mRNA (Fig. 4b). For example, the exon located between E1 and E2, named $\mathrm{E} 1 \mathrm{~A}$, is present in the only transcript that potentially undergoes NMD (MAPT-011, ENST00000571311/ENST0 0000625688) (Fig. 4b). In addition, we identified exon $\mathrm{E} 4 \mathrm{~B}$, which is positioned between E4A and E5 and is spliced to E5, producing a non-coding but processed transcript composed of two exons (MAPT-012, ENST00000577017/ENST00000627800) (Fig. 4b).

Other exons generated by the extension of known exons have been found in particular isoforms in Ensembl database. Exon $\mathrm{E}_{4} \mathrm{~A}_{\text {Long }}$ has been described in MAPT transcripts as another spliced form of exon 4A [41] (see above). $\mathrm{E}_{4} \mathrm{~A}_{\text {Long }}$ may also be the only exon in a short transcript listed in Ensembl database (MAPT-010 ENST00 000576238/ENST00000625417) (Fig. 4b). Another example is extended E3 (E3 $3_{\mathrm{Ext}}, 5658 \mathrm{nt}$ versus E3, $87 \mathrm{nt}$ ), which may be the first exon in the MAPT-009 transcript (ENST00000576518/ENST00000626880) (Fig. 4b). Exon E3 $3_{\text {Ext }}$ is composed of exons E3 and E4, the 1603 nt upstream of E3 and the entire retained intron between E3 and E4 (3903 nt) (Fig. 4b). E3 $3_{\text {Ext }}$ may be a partially coding exon because an ATG is located 100 nt before E4 and is spliced to exon 5, encoding a protein that lacks part of the $5^{\prime}$ region that contains the acidic projection domain (Fig. 4b). Because the alternative exons E4A, E6, and E10 are excluded from this transcript, it may be translated more precisely in this shortened form during fetal development. Interestingly, if this transcript exists, then it has a short 3' UTR. Another example of an extended exon is extended exon $\mathrm{E} 4$ ( $\left.\mathrm{E} 4_{\mathrm{Ext}}\right)$, which corresponds to exon E4 in-frame with partial intronic sequences (2883 nt upstream and $2066 \mathrm{nt}$ downstream) and which may be the only exon in the non-coding transcript MAPT-014 (ENST00000572440/ENST00000628437) (Fig. 4b). Certainly, the existence of these two latter transcripts must be confirmed under physiological conditions.

\section{Splicing and pathology}

Defects in splicing can be pathological events that lead to or have roles in tauopathy-type neurodegenerative processes. Indeed, missplicing has been clearly associated with certain familial tauopathies, such as FTDP-17 and DM (reviewed in $[24,134])$. These pathologies have been associated with either mutations in MAPT cis-elements (FTDP-17) (review in [61]) or with microsatellite expansion in the non-coding regions of various genes, leading to variations in the expression of splicing factors belonging to the CELF and MBNL families (DM, reviewed in [24]). Notably, numerous mutations in MAPT are located in or near E10 (upstream and downstream), favoring E10 inclusion either by destabilizing a stem-loop structure that encourages access to the $5^{\prime}$ splice site or by modifying splicing factor or U1/E6 snRNP binding sites (reviewed in [61]). For sporadic tauopathies, the MAPT haplotype may influence splicing, as described above. Moderate Tau missplicing events have also been observed in numerous other tauopathies, such as AD (reviewed in [24]). In AD and PSP, modified miRNA expression may result in alterations in the expression of certain splicing regulatory factors, which would then influence Tau splicing $[149,150]$. As such, the splicing pattern of MAPT transcripts could be determinant in tauopathy-type neurodegenerative processes. Consistent with this hypothesis, none of the mouse transgenic models have reproduced Tau pathology in the absence of a Tau mutation in the coding region. However, Tau pathology has been observed in mouse models when the human Tau gene is expressed in the absence of endogenous MAPT expression. These observations suggest that the correct ratio between the differentially expressed isoforms is determinant in the tauopathy process in the absence of Tau coding mutations. Thus, the difficulty in obtaining animal models that reproduce tauopathies in the absence of a Tau mutation most likely results from the $M A P T$ splicing pattern, which differs among animal species [151-155]. For example, exon 10 inclusion is highly increased in mouse and rat brains, whereas exon 2 inclusion is observed less frequently in mice compared with humans. Similarly, differences in the $3^{\prime}$ ends of the transcripts, as described below (section 3.3), may stem from 
splicing differences that potentially interfere with the human specificity of the tauopathy process. However, the contribution of other undetermined factors cannot be excluded at this point.

\section{3' UTR/alternative termination sites: Roles of RNA stability and localization}

The 2 and $6 \mathrm{~kb}$ forms of mature Tau RNA are generated from different 3' UTRs. Indeed, two alternative polyadenylation sites followed by a short poly(A) sequence located at a distance of approximately $4000 \mathrm{nt}$ have been found in different animal species [74, 115, 120, 156] (Fig. 3). Thus, at least two transcription termination sites could be used, resulting in transcripts with short or long 3' UTRs. Interestingly, the first polyadenylation site is located within an intronic sequence that is deleted in some transcripts from various animal species. Indeed, in some Ensemble database transcripts from mouse, rat and cow, E14 is separated from E13 by a short intronic sequence of approximately $900 \mathrm{nt}[148,157]$. The splicing of E13 to E14 results in extension of the C-terminus of the protein and truncation of the 3' UTR. In humans, the short intronic region between E13 and E14 is always retained, as described in the literature [74] and databases such as Ensembl. Thus, the splicing of E13/E14 may be a feature that differs between animals and humans.

The 3' UTR may contain cis-elements that decrease Tau RNA expression. Indeed, binding sites for miR-34a and miR-34c-5p have been reported that lead to decreased Tau RNA and protein expression $[45,156]$. Interestingly, increased Tau expression and decreased miR-34C-5p expression have been correlated with the chemoresistance of gastric cancer to paclitaxel [45]. Recent studies have demonstrated a role of miR-485-5p in axonal development and Tau expression downregulation during synaptic plasticity in hippocampal rat neurons. The Tau 3' UTR sequence has two possible miR-485-5p binding sites [158] and contains a target sequence for miR-132-3p, which is strongly downregulated in the brains of AD patients [149]. However, a mutation in the binding site does not completely abolish miR-132 activity, suggesting that other indirect mechanisms exist by which miR-132 affects Tau expression.

In rat transcripts, a 240-nt region in the 3' UTR has been implicated in RNA stability and axonal localization [159-161]. Several proteins, such as HuD (an Elav protein family member), insulin-like growth factor mRNAbinding protein IMP-1, Ras-regulatory protein G3BP, interleukin enhancer binding factor 3 (Ilf3) and NF90, bind to this sequence and are potentially involved in the axonal localization of these transcripts [162]. Unfortunately, no such data are available in humans, and these data must be generated to determine whether similar mechanisms protect human RNA and guide transcripts to their proper locations.

\section{Conclusion: The hidden facets of Tau gene expression}

The aim of this review was to highlight the different steps of MAPT gene expression regulation at the DNA and RNA levels. We focused on the following three aspects of the influence of DNA sequence on MAPT expression: repeated sequences, CpG islands and haplotypes. Notably, scarce data concerning repeated sequences have been reported in the literature, whereas CpG islands and haplotypes are beginning to be well documented. Functional interest in repeated sequences has recently been described in the literature for other genes. For $M A P T$, the report of the role of $\mathrm{SSR}_{58}$ in E10 insertion confirms the interest in such studies [73]. Concerning the regulation of RNA expression, we focused on the potential roles of UTR sequences and alternatively spliced isoforms. Additional data are necessary to confirm or exclude the possible existence of another promoter. Furthermore, differences exist between isoforms reported in the literature and those reported in databases, suggesting that some splicing possibilities remain to be explored. Data regarding Tau isoforms reported in the literature primarily concern the nervous system. However, Tau (transcripts/proteins) is expressed in other tissues, and its expression may play roles in some pathologies, such as cancer and IBM. Thus, increasing our understanding of the isoforms expressed in these different tissues and of the regulation of their expression, which may differ from those in the brain (for example, different promoters and polyadenylation sites) is of interest. In addition to the isoforms described in the literature, the data from databases suggest the possible existence of shortened Tau isoforms, noncoding transcripts and one transcript that may undergo $\mathrm{NMD}$, thereby bringing into question the roles of these hypothetical forms. Finally, the Tau sequences present in databases also suggest the possible existence of a long noncoding MAPT RNA and 3 MAPT anti-sense isoforms; however, these sequences have not yet been reported in the literature. Therefore, they were not discussed here because of the lack of information. Knowledge of these particular Tau transcripts will most likely increase our understanding of Tau expression regulation.

\section{Competing interests}

The authors declare that they have no competing interests.

\section{Authors' contributions}

$M L C B$ and $B L$ wrote the manuscript. $L B$ and NS provided intellectual input and editorial suggestions. All of the authors read and approved the final manuscript.

\section{Acknowledgments}

This work was supported by funding from INSERM, CNRS, IMPRT, University of Lille Nord de France, Lille County Hospital (CHRU-Lille), DISTALZ (Development of Innovative Strategies for a Transdisciplinary approach to 
ALZheimer's disease) (Excellence Laboratory), FRM (Fondation pour la Recherche Médicale), AFM, and ANR Neurosplice of Tau.

\section{Received: 21 April 2015 Accepted: 30 June 2015} Published online: 14 July 2015

\section{References}

1. Weingarten MD, Lockwood AH, Hwo SY, Kirschner MW. A protein factor essential for microtubule assembly. Proc Natl Acad Sci U S A. 1975;72:1858-62.

2. Ballatore C, Lee VM, Trojanowski JQ. Tau-mediated neurodegeneration in Alzheimer's disease and related disorders. Nat Rev Neurosci. 2007:8:663-72.

3. Sergeant N, Delacourte A, Buee L. Tau protein as a differential biomarker of tauopathies. Biochim Biophys Acta. 1739;2005:179-97.

4. Baird FJ, Bennett CL. Microtubule defects \& Neurodegeneration. J Genet Syndr Gene Ther. 2013;4:203.

5. Scholz T, Mandelkow E. Transport and diffusion of Tau protein in neurons. Cell Mol Life Sci. 2014;71:3139-50.

6. Boehm J. A 'danse macabre': tau and Fyn in STEP with amyloid beta to facilitate induction of synaptic depression and excitotoxicity. Eur J Neurosci. 2013;37:1925-30

7. Spires-Jones TL, Hyman BT. The Intersection of Amyloid Beta and Tau at Synapses in Alzheimer's Disease. Neuron. 2014;82:756-71.

8. Sultan A, Nesslany F, Violet M, Begard S, Loyens A, Talahari S, et al. Nuclear tau, a key player in neuronal DNA protection. J Biol Chem. 2011;286:4566-75.

9. Violet M, Delattre L, Tardivel M, Sultan A, Chauderlier A, Caillierez R, et al. A major role for Tau in neuronal DNA and RNA protection in vivo under physiological and hyperthermic conditions. Front Cell Neurosci. 2014;8:84.

10. Schraen-Maschke S, Sergeant N, Dhaenens CM, Bombois S, Deramecourt V, Caillet-Boudin ML, et al. Tau as a biomarker of neurodegenerative diseases. Biomark Med. 2008;2:363-84.

11. Goedert M, Ghetti B, Spillantini MG. Frontotemporal dementia: implications for understanding Alzheimer disease. Cold Spring Harb Perspect Med. 2012;2:a006254.

12. Kon T, Mori F, Tanji K, Miki Y, Tomiyama M, Baba M, et al. Abnormal tau deposition in neurons, but not in glial cells in the cerebral tissue surrounding arteriovenous malformation. Neuropathology. 2012;32:267-71.

13. Brat DJ, Gearing M, Goldthwaite PT, Wainer BH, Burger PC. Tau-associated neuropathology in ganglion cell tumours increases with patient age but appears unrelated to ApoE genotype. Neuropathol Appl Neurobiol. 2001;27:197-205.

14. Oberc-Greenwood MA, McKeever PE, Kornblith PL, Smith BH. A human ganglioglioma containing paired helical filaments. Hum Pathol. 1984;15:834-8

15. Ikeda K, Akiyama H, Kondo H, Arai T, Arai N, Yagishita S. Numerous glial fibrillary tangles in oligodendroglia in cases of subacute sclerosing panencephalitis with neurofibrillary tangles. Neurosci Lett. 1995;194:133-5.

16. Hof PR, Charpiot A, Delacourte A, Buee L, Purohit D, Perl DP, et al. Distribution of neurofibrillary tangles and senile plaques in the cerebral cortex in postencephalitic parkinsonism. Neurosci Lett. 1992:139:10-4.

17. Moran MA, Probst A, Navarro C, Gomez-Ramos P. Alzheimer's disease-type neurofibrillary degeneration in verrucose dysplasias of the cerebral cortex. Acta Neuropathol. 1995;90:356-65.

18. Ball MJ, Nuttall K. Neurofibrillary tangles, granulovacuolar degeneration, and neuron loss in Down Syndrome: quantitative comparison with Alzheimer dementia. Ann Neurol. 1980;7:462-5.

19. Vermersch $P$, Sergeant N, Ruchoux MM, Hofmann-Radvanyi H, Wattez A, Petit $\mathrm{H}$, et al. Specific tau variants in the brains of patients with myotonic dystrophy. Neurology. 1996;47:711-7.

20. Hirano A, Malamud N, Kurland LT. Parkinsonism-dementia complex, an endemic disease on the island of Guam. II Pathological features Brain. 1961;84:662-79.

21. Hof PR, Bouras C, Buee L, Delacourte A, Perl DP, Morrison JH. Differential distribution of neurofibrillary tangles in the cerebral cortex of dementia pugilistica and Alzheimer's disease cases. Acta Neuropathol. 1992;85:23-30.

22. Tokuda T, Ikeda S, Yanagisawa N, Ihara Y, Glenner GG. Re-examination of ex-boxers' brains using immunohistochemistry with antibodies to amyloid beta-protein and tau protein. Acta Neuropathol. 1991;82:280-5.
23. Fernandez-Nogales M, Cabrera JR, Santos-Galindo M, Hoozemans JJ, Ferrer I, Rozemuller AJ, et al. Huntington's disease is a four-repeat tauopathy with tau nuclear rods. Nat Med. 2014;20:881-5.

24. Caillet-Boudin ML, Fernandez-Gomez FJ, Tran H, Dhaenens CM, Buee L, Sergeant N. Brain pathology in myotonic dystrophy: when tauopathy meets spliceopathy and RNAopathy. Front Mol Neurosci. 2014;6:57.

25. Mackenzie IR, Neumann M, Bigio EH, Cairns NJ, Alafuzoff I, Kril J, et al. Nomenclature for neuropathologic subtypes of frontotemporal lobar degeneration: consensus recommendations. Acta Neuropathol. 2009;117:15-8

26. Shi J, Shaw CL, Du Plessis D, Richardson AM, Bailey KL, Julien C, et al. Histopathological changes underlying frontotemporal lobar degeneration with clinicopathological correlation. Acta Neuropathol. 2005;110:501-12.

27. Zhukareva V, Vogelsberg-Ragaglia V, Van Deerlin VM, Bruce J, Shuck T, Grossman M, et al. Loss of brain tau defines novel sporadic and familial tauopathies with frontotemporal dementia. Ann Neurol. 2001;49:165-75.

28. Lattante S, Rouleau GA, Kabashi E. TARDBP and FUS mutations associated with amyotrophic lateral sclerosis: summary and update. Hum Mutat. 2013;34:812-26.

29. Dubourg C, Sanlaville D, Doco-Fenzy M, Le Caignec C, Missirian C, Jaillard S, et al. Clinical and molecular characterization of 17q21.31 microdeletion syndrome in 14 French patients with mental retardation. Eur J Med Genet. 2011;54:144-51.

30. Kirchhoff M, Bisgaard AM, Duno M, Hansen FJ, Schwartz M. A 17q21.31 microduplication, reciprocal to the newly described 17q21.31 microdeletion, in a girl with severe psychomotor developmental delay and dysmorphic craniofacial features. Eur J Med Genet. 2007:50:256-63.

31. Sharkey FH, Morrison N, Murray R, Iremonger J, Stephen J, Maher E, et al. 17q21.31 microdeletion syndrome: further expanding the clinical phenotype. Cytogenet Genome Res. 2009;127:61-6.

32. Shaw-Smith C, Pittman AM, Willatt L, Martin H, Rickman L, Gribble S, et al. Microdeletion encompassing MAPT at chromosome $17 q 21.3$ is associated with developmental delay and learning disability. Nat Genet. 2006;38:1032-7.

33. Desikan RS, Schork AJ, Wang Y, Witoelar A, Sharma M, McEvoy LK, Holland D, Brewer JB, Chen CH, Thompson WK, et al.: Genetic overlap between Alzheimer's disease and Parkinson's disease at the MAPT locus. Mol Psychiatry 2015, doi: 10.1038/mp.2015.6

34. Edwards TL, Scott WK, Almonte C, Burt A, Powell EH, Beecham GW, et al. Genome-wide association study confirms SNPs in SNCA and the MAPT region as common risk factors for Parkinson disease. Ann Hum Genet. 2010:74:97-109.

35. Simon-Sanchez J, Schulte C, Bras JM, Sharma M, Gibbs JR, Berg D, et al. Genome-wide association study reveals genetic risk underlying Parkinson's disease. Nat Genet. 2009;41:1308-12.

36. Askanas V, Engel WK, Bilak M, Alvarez RB, Selkoe DJ. Twisted tubulofilaments of inclusion body myositis muscle resemble paired helical filaments of Alzheimer brain and contain hyperphosphorylated tau. Am J Pathol. 1994;144:177-87.

37. Maurage CA, Bussiere T, Sergeant N, Ghesteem A, Figarella-Branger D, Ruchoux MM, et al. Tau aggregates are abnormally phosphorylated in inclusion body myositis and have an immunoelectrophoretic profile distinct from other tauopathies. Neuropathol Appl Neurobiol. 2004;30:624-34.

38. Matrone MA, Whipple RA, Thompson K, Cho EH, Vitolo MI, Balzer EM, et al. Metastatic breast tumors express increased tau, which promotes microtentacle formation and the reattachment of detached breast tumor cells. Oncogene. 2010;29:3217-27.

39. Pusztai L, Jeong JH, Gong Y, Ross JS, Kim C, Paik S, et al. Evaluation of microtubule-associated protein-Tau expression as a prognostic and predictive marker in the NSABP-B 28 randomized clinical trial. J Clin Oncol. 2009:27:4287-92.

40. Cirak Y, Sarsik B, Cakar B, Sen S, Simsir A, Uslu R. Predictive and prognostic values of Tau and BubR1 protein in prostate cancer and their relationship to the Gleason score. Med Oncol. 2013;30:526.

41. Souter S, Lee G. Microtubule-associated protein tau in human prostate cancer cells: isoforms, phosphorylation, and interactions. J Cell Biochem. 2009;108:555-64

42. Fekete T, Raso E, Pete I, Tegze B, Liko I, Munkacsy G, et al. Meta-analysis of gene expression profiles associated with histological classification and survival in 829 ovarian cancer samples. Int J Cancer. 2012;131:95-105. 
43. Smoter M, Bodnar L, Grala B, Stec R, Zieniuk K, Kozlowski W, et al. Tau protein as a potential predictive marker in epithelial ovarian cancer patients treated with paclitaxel/platinum first-line chemotherapy. J Exp Clin Cancer Res. 2013:32:25.

44. Wosnitzer MS, Domingo-Domenech J, Castillo-Martin M, Ritch C, Mansukhani M, Petrylack DP, et al. Predictive value of microtubule associated proteins tau and stathmin in patients with nonmuscle invasive bladder cancer receiving adjuvant intravesical taxane therapy. J Urol. 2011;186:2094-100.

45. Wu H, Huang M, Lu M, Zhu W, Shu Y, Cao P, et al. Regulation of microtubule-associated protein tau (MAPT) by miR-34c-5p determines the chemosensitivity of gastric cancer to paclitaxel. Cancer Chemother Pharmacol. 2013;71:1159-71.

46. Wang K, Deng QT, Liao N, Zhang GC, Liu YH, Xu FP, et al. Tau expression correlated with breast cancer sensitivity to taxanes-based neoadjuvant chemotherapy. Tumour Biol. 2013;34:33-8.

47. Andre F, Hatzis C, Anderson K, Sotiriou C, Mazouni C, Mejia J, et al. Microtubule-associated protein-tau is a bifunctional predictor of endocrine sensitivity and chemotherapy resistance in estrogen receptor-positive breast cancer. Clin Cancer Res. 2007;13:2061-7.

48. Baquero MT, Lostritto K, Gustavson MD, Bassi KA, Appia F, Camp RL, et al. Evaluation of prognostic and predictive value of microtubule associated protein tau in two independent cohorts. Breast Cancer Res. 2011;13:R85.

49. Im S, Yoo C, Jung JH, Jeon YW, Suh YJ, Lee YS, et al. Microtubule-Associated Protein Tau, alpha-Tubulin and betalll-Tubulin Expression in Breast Cancer. Korean J Pathol. 2013;47:534-40

50. Irshad S, Gillett C, Pinder SE, A'Hern RP, Dowsett M, Ellis IO, et al. Assessment of microtubule-associated protein (MAP)-Tau expression as a predictive and prognostic marker in TACT; a trial assessing substitution of sequential docetaxel for FEC as adjuvant chemotherapy for early breast cancer. Breast Cancer Res Treat. 2014;144:331-41.

51. Li ZH, Xiong QY, Tu JH, Gong Y, Qiu W, Zhang HQ, et al. Tau proteins expressions in advanced breast cancer and its significance in taxane-containing neoadjuvant chemotherapy. Med Oncol. 2013;30:591.

52. Mimori K, Sadanaga N, Yoshikawa Y, Ishikawa K, Hashimoto M, Tanaka F, et al. Reduced tau expression in gastric cancer can identify candidates for successful Paclitaxel treatment. Br J Cancer. 2006:94:1894-7.

53. Spicakova T, O'Brien MM, Duran GE, Sweet-Cordero A, Sikic BI. Expression and silencing of the microtubule-associated protein Tau in breast cancer cells. Mol Cancer Ther. 2010;9:2970-81.

54. Steffensen KD, Smoter M, Waldstrom M, Grala B, Bodnar L, Stec R, et al. Resistance to first line platinum paclitaxel chemotherapy in serous epithelial ovarian cancer: the prediction value of ERCC1 and Tau expression. Int J Oncol. 2014:44:1736-44.

55. Wang Q, Wang N, Shao G, Qian J, Shen D, Fei Y, et al. Relationship between gastric cancer tau protein expression and paclitaxel sensitivity. Pathol Oncol Res. 2013;19:429-35.

56. Won HS, Lee KE, Sung SH, Choi MY, Jo JY, Nam EM, et al. Topoisomerase II alpha and microtubule-associated protein-tau as a predictive marker in axillary lymph node positive breast cancer. Tumori. 2014;100:80-6.

57. Andreadis A. Tau gene alternative splicing: expression patterns, regulation and modulation of function in normal brain and neurodegenerative diseases. Biochim Biophys Acta. 1739;2005:91-103.

58. Andreadis A. Tau splicing and the intricacies of dementia. J Cell Physiol. 2012:227:1220-5.

59. Borroni B, Agosti C, Magnani E, Di Luca M, Padovani A. Genetic bases of Progressive Supranuclear Palsy: the MAPT tau disease. Curr Med Chem. 2011;18:2655-60.

60. Caffrey TM, Wade-Martins R. Functional MAPT haplotypes: bridging the gap between genotype and neuropathology. Neurobiol Dis. 2007;27:1-10.

61. Niblock M, Gallo JM. Tau alternative splicing in familial and sporadic tauopathies. Biochem Soc Trans. 2012;40:677-80

62. Wang C, Huang S. Nuclear function of Alus. Nucleus. 2014:5:131-7.

63. Levy A, Sela N, Ast G. TranspoGene and microTranspoGene: transposed elements influence on the transcriptome of seven vertebrates and invertebrates. Nucleic Acids Res. 2008;36:D47-52.

64. Maloney B, Lahiri DK. Structural and functional characterization of $\mathrm{H}_{2}$ haplotype MAPT promoter: unique neurospecific domains and a hypoxia-inducible element would enhance rationally targeted tauopathy research for Alzheimer's disease. Gene. 2012;501:63-78.

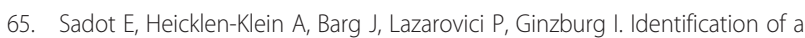
tau promoter region mediating tissue-specific-regulated expression in PC12 cells. J Mol Biol. 1996;256:805-12.

66. Lander ES, Linton LM, Birren B, Nusbaum C, Zody MC, Baldwin J, et al. Initial sequencing and analysis of the human genome. Nature. 2001;409:860-921.

67. Yanez-Cuna JO, Arnold CD, Stampfel G, Boryn LM, Gerlach D, Rath M, et al. Dissection of thousands of cell type-specific enhancers identifies dinucleotide repeat motifs as general enhancer features. Genome Res. 2014;24:1147-56.

68. Mohan A. Goodwin M. RNA-protein interactions in unstable microsatellite diseases. Brain Res: Swanson MS; 2014.

69. Wojciechowska M, Krzyzosiak WJ. Cellular toxicity of expanded RNA repeats: focus on RNA foci. Hum Mol Genet. 2011;20:3811-21.

70. Benson G. Tandem repeats finder: a program to analyze DNA sequences. Nucleic Acids Res. 1999:27:573-80.

71. Conrad C, Andreadis A, Trojanowski JQ, Dickson DW, Kang D, Chen X, et al. Genetic evidence for the involvement of tau in progressive supranuclear palsy. Ann Neurol. 1997:41:277-81.

72. Conrad C, Amano N, Andreadis A, Xia Y, Namekataf K, Oyama F, et al. Differences in a dinucleotide repeat polymorphism in the tau gene between Caucasian and Japanese populations: implication for progressive supranuclear palsy. Neurosci Lett. 1998;250:135-7.

73. Holzer M, Craxton M, Jakes $\mathrm{R}$, Arendt $\mathrm{T}$, Goedert M. Tau gene (MAPT) sequence variation among primates. Gene. 2004;341:313-22.

74. Poorkaj P, Kas A, D'Souza I, Zhou Y, Pham Q, Stone M, et al. A genomic sequence analysis of the mouse and human microtubule-associated protein tau. Mamm Genome. 2001:12:700-12.

75. Andreadis A, Brown WM, Kosik KS. Structure and novel exons of the human tau gene. Biochemistry. 1992;31:10626-33.

76. Gardiner-Garden M, Frommer M. CpG islands in vertebrate genomes. J Mol Biol. 1987;196:261-82.

77. Andreadis A, Wagner BK, Broderick JA, Kosik KS. A tau promoter region without neuronal specificity. J Neurochem. 1996;66:2257-63.

78. Kent WJ, Sugnet CW, Furey TS, Roskin KM, Pringle TH, Zahler AM, et al. The human genome browser at UCSC. Genome Res. 2002;12:996-1006.

79. Karolchik D, Barber GP, Casper J, Clawson H, Cline MS, Diekhans M, et al. The UCSC Genome Browser database: 2014 update. Nucleic Acids Res. 2002:42:D764-770.

80. Maunakea AK, Nagarajan RP, Bilenky M, Ballinger TJ, D'Souza C, Fouse SD, et al. Conserved role of intragenic DNA methylation in regulating alternative promoters. Nature. 2010;466:253-7.

81. Li LC, Dahiya R. MethPrimer: designing primers for methylation PCRs. Bioinformatics. 2002;18:1427-31.

82. Coupland KG, Mellick GD, Silburn PA, Mather K, Armstrong NJ, Sachdev PS et al. DNA methylation of the MAPT gene in Parkinson's disease cohorts and modulation by vitamin E In Vitro. Mov Disord. 2014;29(13):1606-14.

83. Iwata A, Nagata K, Hatsuta H, Takuma H, Bundo M, Iwamoto K, et al. Altered CpG methylation in sporadic Alzheimer's disease is associated with APP and MAPT dysregulation. Hum Mol Genet. 2014;23:648-56.

84. Barrachina M, Ferrer I. DNA methylation of Alzheimer disease and tauopathyrelated genes in postmortem brain. J Neuropathol Exp Neurol. 2009;68:880-91.

85. Schraen-Maschke S, Dhaenens CM, Delacourte A, Sablonniere B. Microtubule-associated protein tau gene: a risk factor in human neurodegenerative diseases. Neurobiol Dis. 2004;15:449-60.

86. Cruts M, Rademakers R, Gijselinck I, van der Zee J, Dermaut B, de Pooter T, et al. Genomic architecture of human 17q21 linked to frontotemporal dementia uncovers a highly homologous family of low-copy repeats in the tau region. Hum Mol Genet. 2005;14:1753-62.

87. Stefansson H, Helgason A, Thorleifsson G, Steinthorsdottir V, Masson G, Barnard J, et al. A common inversion under selection in Europeans. Nat Genet. 2005;37:129-37.

88. Rao PN, Li W, Vissers LE, Veltman JA, Ophoff RA. Recurrent inversion events at 17q21.31 microdeletion locus are linked to the MAPT H2 haplotype. Cytogenet Genome Res. 2010;129:275-9.

89. Pittman AM, Myers AJ, Duckworth J, Bryden L, Hanson M, Abou-Sleiman P, et al. The structure of the tau haplotype in controls and in progressive supranuclear palsy. Hum Mol Genet. 2004;13:1267-74.

90. Cruchaga C, Vidal-Taboada JM, Ezquerra M, Lorenzo E, Martinez-Lage P, Blazquez M, et al. 5'-Upstream variants of CRHR1 and MAPT genes associated with age at onset in progressive supranuclear palsy and cortical basal degeneration. Neurobiol Dis. 2009;33:164-70. 
91. Ezquerra M, Pastor P, Gaig C, Vidal-Taboada JM, Cruchaga C, Munoz E, et al. Different MAPT haplotypes are associated with Parkinson's disease and progressive supranuclear palsy. Neurobiol Aging. 2011;32:547. e511-546.

92. Myers AJ, Kaleem M, Marlowe L, Pittman AM, Lees AJ, Fung HC, et al. The H1c haplotype at the MAPT locus is associated with Alzheimer's disease. Hum Mol Genet. 2005;14:2399-404.

93. Pittman AM, Myers AJ, Abou-Sleiman P, Fung HC, Kaleem M, Marlowe L, et al. Linkage disequilibrium fine mapping and haplotype association analysis of the tau gene in progressive supranuclear palsy and corticobasal degeneration. J Med Genet. 2005;42:837-46.

94. Santa-Maria I, Haggiagi A, Liu X, Wasserscheid J, Nelson PT, Dewar K, et al. The MAPT H1 haplotype is associated with tangle-predominant dementia. Acta Neuropathol. 2012;124:693-704.

95. Sobrido MJ, Abu-Khalil A, Weintraub S, Johnson N, Quinn B, Cummings $J$, et al. Possible association of the tau $\mathrm{H} 1 / \mathrm{H} 1$ genotype with primary progressive aphasia. Neurology. 2003;60:862-4.

96. Tobin JE, Latourelle JC, Lew MF, Klein C, Suchowersky O, Shill HA, et al. Haplotypes and gene expression implicate the MAPT region for Parkinson disease: the GenePD Study. Neurology. 2008;71:28-34.

97. Togo T, Sahara N, Yen SH, Cookson N, Ishizawa T, Hutton M, et al. Argyrophilic grain disease is a sporadic 4-repeat tauopathy. J Neuropathol Exp Neurol. 2002:61:547-56.

98. Sobrido MJ, Miller BL, Havlioglu N, Zhukareva V, Jiang Z, Nasreddine ZS, et al. Novel tau polymorphisms, tau haplotypes, and splicing in familial and sporadic frontotemporal dementia. Arch Neurol. 2003;60:698-702.

99. Russ C, Lovestone S, Baker M, Pickering-Brown SM, Andersen PM, Furlong R, et al. The extended haplotype of the microtubule associated protein tau gene is not associated with Pick's disease. Neurosci Lett. 2001;299:156-8.

100. Li Y, Chen JA, Sears RL, Gao F, Klein ED, Karydas A, et al. An epigenetic signature in peripheral blood associated with the haplotype on 17q21.31, a risk factor for neurodegenerative tauopathy. PLoS Genet. 2014;10:e1004211.

101. Myers AJ, Pittman AM, Zhao AS, Rohrer K, Kaleem M, Marlowe L, et al. The MAPT H1C risk haplotype is associated with increased expression of tau and especially of 4 repeat containing transcripts. Neurobiol Dis. 2007;25:561-70.

102. Caffrey TM, Joachim C, Wade-Martins R. Haplotype-specific expression of the $\mathrm{N}$-terminal exons 2 and 3 at the human MAPT locus. Neurobiol Aging. 2008;29:1923-9.

103. Zhong Q, Congdon EE, Nagaraja HN, Kuret J. Tau isoform composition influences rate and extent of filament formation. J Biol Chem. 2012;287:20711-9.

104. Hayesmoore JB, Bray NJ, Cross WC, Owen MJ, O'Donovan MC, Morris HR. The effect of age and the H1c MAPT haplotype on MAPT expression in human brain. Neurobiol Aging. 2009;30:1652-6.

105. Kwok JB, Teber ET, Loy C, Hallupp M, Nicholson G, Mellick GD, et al. Tau haplotypes regulate transcription and are associated with Parkinson's disease. Ann Neurol. 2004:55:329-34.

106. Rademakers R, Melquist S, Cruts M, Theuns J, Del-Favero J, Poorkaj P, et al. High-density SNP haplotyping suggests altered regulation of tau gene expression in progressive supranuclear palsy. Hum Mol Genet. 2005;14:3281-92.

107. Colom-Cadena M, Gelpi E, Marti MJ, Charif S, Dols-Icardo O, Blesa R, et al. MAPT $\mathrm{H} 1$ haplotype is associated with enhanced alpha-synuclein deposition in dementia with Lewy bodies. Neurobiol Aging. 2013;34:936-42.

108. Compta Y, Parkkinen L, O'Sullivan SS, Vandrovcova J, Holton JL, Collins C, et al. Lewy- and Alzheimer-type pathologies in Parkinson's disease dementia: which is more important? Brain. 2011;134:1493-505.

109. Wider C, Ross OA, Nishioka K, Heckman MG, Vilarino-Guell C, Jasinska-Myga $B$, et al. An evaluation of the impact of MAPT, SNCA and APOE on the burden of Alzheimer's and Lewy body pathology. J Neurol Neurosurg Psychiatry. 2012;83:424-9.

110. Bombois S, Duhamel A, Salleron J, Deramecourt V, Mackowiak MA, Deken V, et al. A new decision tree combining Abeta 1-42 and p-Tau levels in Alzheimer's diagnosis. Curr Alzheimer Res. 2013;10:357-64.

111. Kauwe JS, Cruchaga C, Mayo K, Fenoglio C, Bertelsen S, Nowotny P, et al. Variation in MAPT is associated with cerebrospinal fluid tau levels in the presence of amyloid-beta deposition. Proc Natl Acad Sci U S A. 2008; 105:8050-4

112. Laws SM, Friedrich P, Diehl-Schmid J, Muller J, Eisele T, Bauml J, et al. Fine mapping of the MAPT locus using quantitative trait analysis identifies possible causal variants in Alzheimer's disease. Mol Psychiatry. 2007;12:510-7.
113. Amadoro G, Corsetti V, Sancesario GM, Lubrano A, Melchiorri G, Bernardini $\mathrm{S}$, et al. Cerebrospinal fluid levels of a 20-22 kDa NH2 fragment of human tau provide a novel neuronal injury biomarker in Alzheimer's disease and other dementias. J Alzheimers Dis. 2014:42:211-26.

114. Goedert M, Spillantini MG, Jakes R, Rutherford D, Crowther RA. Multiple isoforms of human microtubule-associated protein tau: sequences and localization in neurofibrillary tangles of Alzheimer's disease. Neuron. 1989:3:519-26.

115. Goedert M, Wischik CM, Crowther RA, Walker JE, Klug A. Cloning and sequencing of the CDNA encoding a core protein of the paired helical filament of Alzheimer disease: identification as the microtubule-associated protein tau. Proc Natl Acad Sci U S A. 1988:85:4051-5.

116. Gu Y, Oyama F, Ihara Y. Tau is widely expressed in rat tissues. J Neurochem. 1996;67:1235-44.

117. Wei ML, Andreadis A. Splicing of a regulated exon reveals additional complexity in the axonal microtubule-associated protein tau. J Neurochem. 1998:70:1346-56.

118. Rouzier R, Rajan R, Wagner P, Hess KR, Gold DL, Stec J, et al. Microtubule-associated protein tau: a marker of paclitaxel sensitivity in breast cancer. Proc Natl Acad Sci U S A. 2005;102:8315-20.

119. Drubin D, Kobayashi S, Kellogg D, Kirschner M. Regulation of microtubule protein levels during cellular morphogenesis in nerve growth factor-treated PC12 cells. J Cell Biol. 1988;106:1583-91.

120. Sadot E, Marx R, Barg J, Behar L, Ginzburg I. Complete sequence of 3'-untranslated region of Tau from rat central nervous system. Implications for mRNA heterogeneity. J Mol Biol. 1994;241:325-31.

121. Gao L, Tucker KL, Andreadis A. Transcriptional regulation of the mouse microtubule-associated protein tau. Biochim Biophys Acta. 2005;1681:175-81.

122. Heicklen-Klein A, Ginzburg I. Tau promoter confers neuronal specificity and binds Sp1 and AP-2. J Neurochem. 2000;75:1408-18.

123. Heicklen-Klein A, Aronov S, Ginzburg I. Tau promoter activity in neuronally differentiated P19 cells. Brain Res. 2000;874:1-9.

124. Strausberg RL, Feingold EA, Grouse LH, Derge JG, Klausner RD, Collins FS, et al. Generation and initial analysis of more than 15,000 full-length human and mouse cDNA sequences. Proc Natl Acad Sci U S A. 2002;99:16899-903.

125. Flicek P, Amode MR, Barrell D, Beal K, Billis K, Brent S, et al. Ensembl 2014. Nucleic Acids Res. 2014;42:D749-755.

126. Maloney B, Lahiri DK. The Alzheimer's amyloid beta-peptide (Abeta) binds a specific DNA Abeta-interacting domain (AbetalD) in the APP, BACE1, and APOE promoters in a sequence-specific manner: characterizing a new regulatory motif. Gene. 2011;488:1-12.

127. Bloom GS. Amyloid-beta and tau: the trigger and bullet in Alzheimer disease pathogenesis. JAMA Neurol. 2014;71:505-8.

128. Ittner LM, Gotz J. Amyloid-beta and tau-a toxic pas de deux in Alzheimer's disease. Nat Rev Neurosci. 2011;12:65-72.

129. Batut $P$, Gingeras TR. RAMPAGE: promoter activity profiling by paired-end sequencing of 5'-complete cDNAs. Curr Protoc Mol Biol. 2013;104:Unit 25B 11.

130. Shabalina SA, Ogurtsov AY, Spiridonov NA, Koonin EV. Evolution at protein ends: major contribution of alternative transcription initiation and termination to the transcriptome and proteome diversity in mammals. Nucleic Acids Res. 2014;42:7132-44.

131. Wang Y, Loomis PA, Zinkowski RP, Binder LI. A novel tau transcript in cultured human neuroblastoma cells expressing nuclear tau. J Cell Biol. 1993;121:257-67.

132. Suske G. The Sp-family of transcription factors. Gene. 1999;238:291-300.

133. Farre D, Roset R, Huerta M, Adsuara JE, Rosello L, Alba MM, et al. Identification of patterns in biological sequences at the ALGGEN server: PROMO and MALGEN. Nucleic Acids Res. 2003;31:3651-3.

134. Qian W, Liu F. Regulation of alternative splicing of tau exon 10. Neurosc Bull. 2014;30:367-77.

135. Lee VM, Goedert M, Trojanowski JQ. Neurodegenerative tauopathies. Annu Rev Neurosci. 2001;24:1121-59.

136. Sergeant N, Bretteville A, Hamdane M, Caillet-Boudin ML, Grognet P, Bombois $S$, et al. Biochemistry of Tau in Alzheimer's disease and related neurological disorders. Expert Rev Proteomics. 2008;5:207-24.

137. Leroy O, Wang J, Maurage CA, Parent M, Cooper T, Buee L, et al. Brain-specific change in alternative splicing of Tau exon 6 in myotonic dystrophy type 1. Biochim Biophys Acta. 1762;2006:460-7.

138. Goedert M, Spillantini MG, Potier MC, Ulrich J, Crowther RA. Cloning and sequencing of the cDNA encoding an isoform of microtubule-associated 
protein tau containing four tandem repeats: differential expression of tau protein mRNAs in human brain. EMBO J. 1989;8:393-9.

139. Spillantini MG, Goedert M. Tau pathology and neurodegeneration. Lancet Neurol. 2013;12:609-22.

140. Goedert M, Spillantini MG, Crowther RA. Cloning of a big tau microtubuleassociated protein characteristic of the peripheral nervous system. Proc Natl Acad Sci U S A. 1992;89:1983-7.

141. Wang J, Tse SW, Andreadis A. Tau exon 6 is regulated by an intricate interplay of trans factors and cis elements, including multiple branch points. J Neurochem. 2007;100:437-45.

142. Luo MH, Leski ML, Andreadis A. Tau isoforms which contain the domain encoded by exon 6 and their role in neurite elongation. J Cell Biochem. 2004:91:880-95.

143. Luo MH, Tse SW, Memmott J, Andreadis A. Novel isoforms of tau that lack the microtubule-binding domain. J Neurochem. 2004;90:340-51.

144. Kanaan NM, Morfini GA, LaPointe NE, Pigino GF, Patterson KR, Song Y, et al. Pathogenic forms of tau inhibit kinesin-dependent axonal transport through a mechanism involving activation of axonal phosphotransferases. J Neurosci. 2011;31:9858-68.

145. Lapointe NE, Horowitz PM, Guillozet-Bongaarts AL, Silva A, Andreadis A, Binder LI. Tau 6D and 6P isoforms inhibit polymerization of full-length tau in vitro. Biochemistry. 2009:48:12290-7.

146. Nelson PT, Stefansson K, Gulcher J, Saper CB. Molecular evolution of tau protein: implications for Alzheimer's disease. J Neurochem. 1996;67:1622-32.

147. Himmler A. Structure of the bovine tau gene: alternatively spliced transcripts generate a protein family. Mol Cell Biol. 1989;9:1389-96.

148. Andreadis A, Nisson PE, Kosik KS, Watkins PC. The exon trapping assay partly discriminates against alternatively spliced exons. Nucleic Acids Res. 1993;21:2217-21

149. Lau P, Bossers K, Janky R, Salta E, Frigerio CS, Barbash S, et al. Alteration of the microRNA network during the progression of Alzheimer's disease. EMBO Mol Med. 2013;5:1613-34.

150. Smith PY, Delay C, Girard J, Papon MA, Planel E, Sergeant N, et al. MicroRNA-132 loss is associated with tau exon 10 inclusion in progressive supranuclear palsy. Hum Mol Genet. 2011;20:4016-24.

151. Duff K, Knight $H$, Refolo LM, Sanders S, Yu X, Picciano M, et al. Characterization of pathology in transgenic mice over-expressing human genomic and cDNA tau transgenes. Neurobiol Dis. 2000;7:87-98.

152. Hanes J, Zilka N, Bartkova M, Caletkova M, Dobrota D, Novak M. Rat tau proteome consists of six tau isoforms: implication for animal models of human tauopathies. J Neurochem. 2009;108:1167-76.

153. Janke C, Beck M, Stahl T, Holzer M, Brauer K, Bigl V, et al. Phylogenetic diversity of the expression of the microtubule-associated protein tau: implications for neurodegenerative disorders. Brain Res Mol Brain Res. 1999:68:119-28.

154. McMillan P, Korvatska E, Poorkaj P, Evstafjeva Z, Robinson L, Greenup L, et al. Tau isoform regulation is region- and cell-specific in mouse brain. J Comp Neurol. 2008;511:788-803.

155. Takuma H, Arawaka S, Mori H. Isoforms changes of tau protein during development in various species. Brain Res Dev Brain Res. 2003;142:121-7.

156. Dickson JR, Kruse C, Montagna DR, Finsen B, Wolfe MS. Alternative polyadenylation and miR-34 family members regulate tau expression. J Neurochem. 2013;127:739-49.

157. Lee G, Cowan N, Kirschner M. The primary structure and heterogeneity of tau protein from mouse brain. Science. 1988;239:285-8.

158. Cohen JE, Lee PR, Fields RD. Systematic identification of 3'-UTR regulatory elements in activity-dependent mRNA stability in hippocampal neurons. Philos Trans R Soc Lond B Biol Sci. 2014;369.

159. Aranda-Abreu GE, Behar L, Chung S, Furneaux H, Ginzburg I. Embryonic lethal abnormal vision-like RNA-binding proteins regulate neurite outgrowth and tau expression in PC12 cells. J Neurosci. 1999;19:6907-17.

160. Aronov S, Aranda G, Behar L, Ginzburg I. Axonal tau mRNA localization coincides with tau protein in living neuronal cells and depends on axonal targeting signal. J Neurosci. 2001;21:6577-87.

161. Aronov S, Marx R, Ginzburg I. Identification of 3'UTR region implicated in tau mRNA stabilization in neuronal cells. J Mol Neurosci. 1999;12:131-45.

162. Larcher JC, Gasmi L, Viranaicken W, Edde B, Bernard R, Ginzburg I, et al. IIf3 and NF90 associate with the axonal targeting element of Tau mRNA. FASEB J. 2004;18:1761-3.

\section{Submit your next manuscript to BioMed Central and take full advantage of:}

- Convenient online submission

- Thorough peer review

- No space constraints or color figure charges

- Immediate publication on acceptance

- Inclusion in PubMed, CAS, Scopus and Google Scholar

- Research which is freely available for redistribution 